\title{
SYNTHESIS AND CHARACTERIZATION OF CALCITE NANO-PARTICLE DERIVED FROM COCKLE SHELL FOR CLINICAL APPLICATION
}

\author{
Nguyen Xuan Thanh Tram ${ }^{1,2}$ \\ ${ }^{1}$ Department of Silicate Materials, Faculty of Materials Technology, Ho Chi Minh City University of \\ Technology, Vietnam National University - Ho Chi Minh City, Ho Chi Minh City, Vietnam, \\ Tel: +84938978389, e-mail: nxttram@hcmut.edu.vn \\ ${ }^{2}$ Department of Biomaterials, Faculty of Dental Science, Kyushu University, Fukuoka, Japan
}

Received Date: June 27, 2019; Revised Date: December 27, 2019; Acceptance Date: January 8, 2020

\begin{abstract}
Calcite nano-particle is suggested as an extremely effective material in the biomedical due to their shape, non-toxic properties and being easily metabolized by cells. In clinical application, calcite nano- particle has to be useful for recovering the surface of tooth. The surface of tooth was often damaged due to wrong tooth care treatment, dental caries and periodontal disease. Because of tooth surface destruction, it could lead to dental hypersensitivity. It is desirable to find a suitable source for supplying calcium to fill in dentinal tubules and later regenerate the tooth surface. This study demonstrated the synthesis and characterization of calcite nanoparticle for its application in dental hypersensitivity treatment. Cockleshell was found to be a suitable source to synthesize calcite. Using cockleshell as raw materials to produce calcite nanoparticle is meaningful for both environmental protection and biomedical application. Therefore, in this study, calcite nano-particle was synthesized using cockleshell as a reproducibility source of calcium carbonate $\left(\mathrm{CaCO}_{3}\right)$ and chitosan as a size-reducing agent. Xray Diffraction (XRD) was used to characterize phase composition of raw materials, as-prepared powder and calcined powder. Transmission Electron Microscopy (TEM) was used to evaluate the size and morphology of powder. Results indicated that calcite nano-particle with size about 50$100 \mathrm{~nm}$ could be obtained. It would be expected to consider for further studies in clinical application.
\end{abstract}

Keywords: Calcite, Hypersensitivity, Nano-particles

\section{Introduction}

Dentine hypersensitivity is a wide spread painful dental problem that can be found in people with tooth sensitivity having their dentinal tubules exposed. These microscopic tubes are perpendicular to the surface of the tooth, and extend to the inner pulp chamber. It is necessary to find a material to supply calcium that could recover the surface of tooth. This material should be in the form of nano-particles so that they could spontaneously spread over every surface of the mouth, both teeth and gums. If they encounter any crevices or holes, they will migrate into them. Whenever the nano-particles encounter a solid surface, they stick there by virtue of the omnipresent molecular attractive forces, such as van der Waal's forces, and electrostatic attraction.

Calcium carbonate $\left(\mathrm{CaCO}_{3}\right)$, is one of the potential sources to supply Calcium, has three polymorphs in nature such as calcite, aragonite and vaterite. Aragonite is the polymorph researched the most among them because of being biocompatible [1]. However, conrcening about the thermodynamic stability, calcite is suggested [2]. Calcite nanoparticle is considered as an extremely effective material in the biomedical due to their 
shape, non-toxic properties and being easily metabolized by all cells. Calcite with nanostructure could supply a calcium sources to retain this ion in supersaturating state in the enamel minerals. Hence, calcite has great potential in preventing of tooth erosion and it could be used for dental hypersensitive treatment.

The bio-system research has been showing many ways to synthesize calcite under different forms and structure from various sources. The cockle belonging to the species of Anadara granosa, a type of sea molluscan is a favourite seafood in South East Asian area. Cockle shell is abundantly available as a by-product from seafood industry after the mussels were consumed. Cockleshell is one of the abundant sources in $\mathrm{CaCO}_{3}$. Some of previous reports stated that $95-99 \%$ amount of cockle shell is $\mathrm{CaCO}_{3}$ in the form of aragonite or calcite [3-6].

In this study, calcite nano-particle was synthesized by dissolution- precipitation method using cockleshell as a reproducibility source of $\mathrm{CaCO}_{3}$ and chitosan as a sizereducing agent. In this way, it was possible to control the properties of calcite nano-particle via adjusting of synthesis temperature and calcination process.

\section{Materials and Method}

\section{Materials Preparation}

Cockleshells were firstly washed to remove dirt. Then, approximately 100 grams cockleshells were boiled at $100^{\circ} \mathrm{C}$ for 30 minutes and dried for 2 days at $110^{\circ} \mathrm{C}$ in the oven. After that, the shells were grounded using agate mortar. Finally, the powder with size approximately $90 \mu \mathrm{m}$ were collected by a stainless laboratory test sieve. The powder then was kept in a glass bottle for further reaction.

Cockleshell powder was dissolved with hydrochloric acid $(\mathrm{HCl}) 37 \%$. Chitosan was dissolved in Acetic Acid and mixed with calcium chloride $\left(\mathrm{CaCl}_{2}\right)$. The mixture was then reacted with sodium carbonate $\left(\mathrm{Na}_{2} \mathrm{CO}_{3}\right)$. The reaction was kept overnight at $80^{\circ} \mathrm{C}$ and $90^{\circ} \mathrm{C}$ under stirring with speed $1000 \mathrm{rpm}$. The solution was filtered several times to obtain as-prepared powder. The as-prepared powder was washed with distilled water then dried and calcined in the furnace at $550^{\circ} \mathrm{C}$ for 6 hours, $600^{\circ} \mathrm{C}$ for 6 hours and 8 hours, and $650^{\circ} \mathrm{C}$ for 2 hours and 6 hours. The calcination temperatures were chosen to remove organic completely and to prevent decomposition reaction. After calcination, obtained powder was ground using agate mortar and characterized for phase composition and morphology.

\section{Characterization}

Composition of the specimen was characterized using powder X-ray diffraction (XRD) analysis. Sample was ground to fine powder and the XRD patterns were recorded using a diffractometer system (D2 Phaser, Bruker AXS GmbH, Karlsruhe, Germany). The size and shape of the particle were observed using Transmission Electron Microscopy (JEM-1400, JEOL, Japan).

\section{Results and Discussion}

The XRD patterns of cockleshell powder (Figure 1a), samples synthesized at different reaction temperatures (Figure 1b), samples calcined at different temperatures within 6 hours (Figure 1c), samples calcined at $600^{\circ} \mathrm{C}$ at different soaking time (Figure 1d), and samples calcined at $650^{\circ} \mathrm{C}$ at different soaking time (Figure 1e) were demonstrated in Figure 1. 

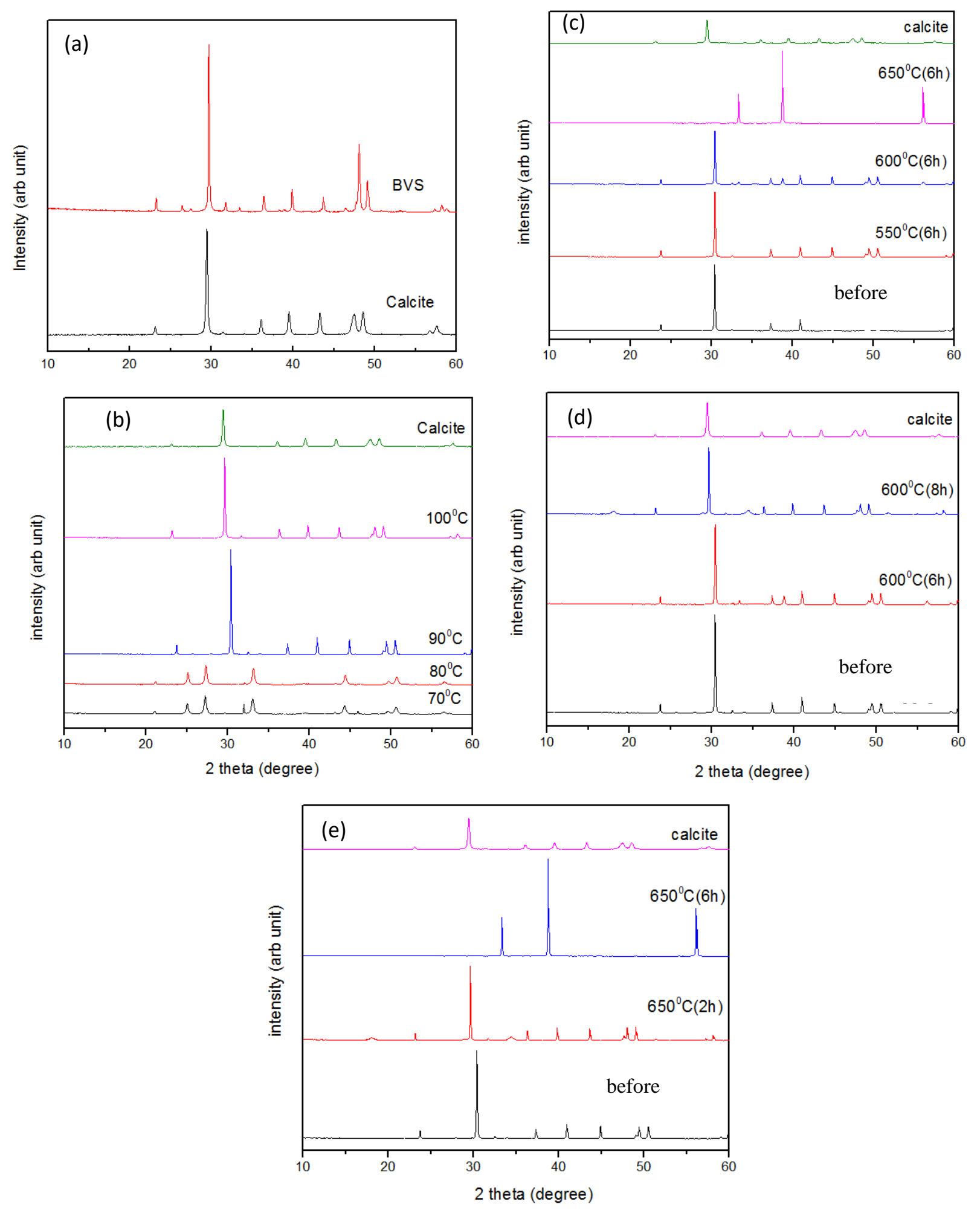

Figure 1. XRD patterns of cockle shells powders (a), samples synthesized at different reaction temperatures (b), samples calcined at different temperatures for 6 hours (c)), samples calcined at $600^{\circ} \mathrm{C}$ with different soaking time (d), and samples calcined at $650^{\circ} \mathrm{C}$ with different soaking time (e) 
Based on the XRD patterns, it showed that the cockleshell powder (BVS) had the same peaks as the calcite; specific spectra at 24, 29, 36, 39, 44, 48 and 57 degree. It was indicated that the cockleshell powder composition is mainly calcite. After chemical treatment, $\mathrm{CaCl}_{2}$ solution reacted with $\mathrm{Na}_{2} \mathrm{CO}_{3}$ completely at $90^{\circ} \mathrm{C}$ and $100^{\circ} \mathrm{C}$, showing with peaks coinciding with the peak of calcite. Conversely, when synthesis was carried out at $70^{\circ} \mathrm{C}$ and $80^{\circ} \mathrm{C}$, reaction between $\mathrm{CaCl}_{2}$ and $\mathrm{Na}_{2} \mathrm{CO}_{3}$ was incomplete. Due to incomplete reaction and other phase transformation, it also showed some extra peaks belonging to other minerals $\mathrm{Na}_{2} \mathrm{CO}_{3}$ (ICDD 18-1208) or vaterite (ICDD 74-1867). The obtained sample $70^{\circ} \mathrm{C}$ and $80^{\circ} \mathrm{C}$ had only Calcite peaks at 23,44 and 50 degree (as showed in Figure1b). The samples of calcined powder at $550^{\circ} \mathrm{C}, 600^{\circ} \mathrm{C}$ soaking for $6 \mathrm{~h}$ and $650^{\circ} \mathrm{C}$ soaking for $2 \mathrm{~h}$ had the characteristic peaks of calcite. On the contrary, samples of calcined powder at $650^{\circ} \mathrm{C}$ soaking for $6 \mathrm{~h}$ appeared peaks of other minerals such as lime (CaO ICDD 37-1497). This could involve to the decomposition of $\mathrm{CaCO}_{3}$ into $\mathrm{CaO}$ and $\mathrm{CO}_{2}$ when calcined at higher temperatures for longer periods of soaking time. Figure 2 illustrated the peaks of pure $\mathrm{CaO}$ powder [6]. It could be seen that the $650^{\circ} \mathrm{C}$-calcined powder had peaks that coincided with the peak of the XRD pattern of $\mathrm{CaO}$ (as shown in Figure 1e).

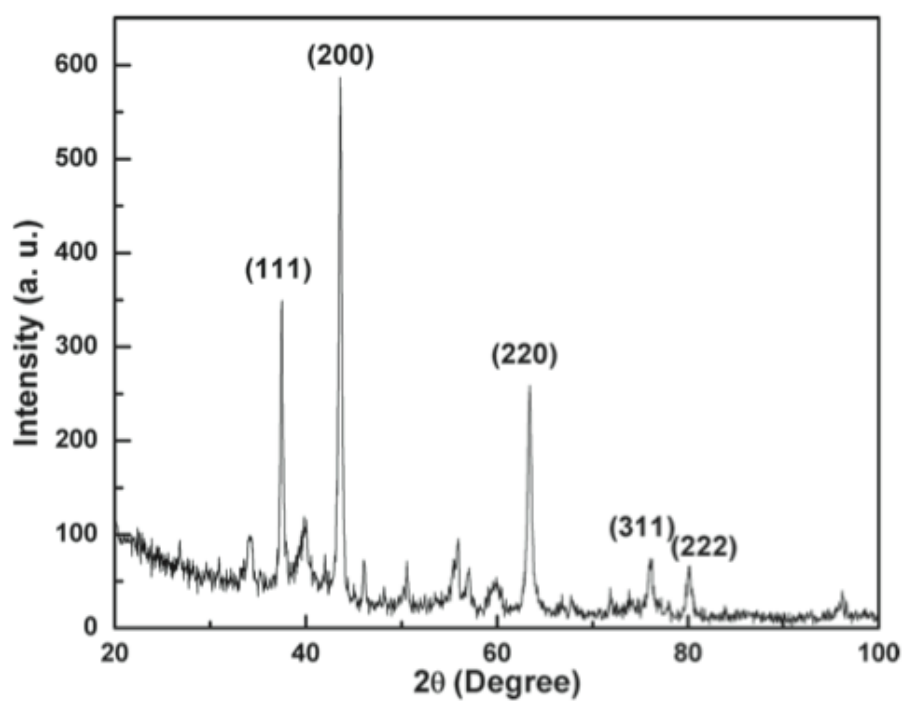

Figure 2. XRD pattern of of nano particle $\mathrm{CaO}$ [7]. Adapted from "Antimicrobial activity of $\mathrm{CaO}$ nanoparticles," by R. Arup, S.S. Gauri, M. Bhattacharya, and J. Bhattacharya, 2013, Journal of Biomedical Nanotechnology, Vol. 9 (9), pp. 15701578. Copyright 2013 by the American Scientific Publishers.

Transmission Electron Microscopy was used to observed morphology of nanopowder. Figure 3 is the TEM images of the raw cockleshell powder (named as BVS) at different magnification and the TEM images of powder calcined at $650^{\circ} \mathrm{C}$ soaking for 2 hours $\left(650^{\circ} \mathrm{C}-2 \mathrm{~h}\right)$ at different magnification. It could be seen that raw cockleshell powder has particle around size of $500 \mathrm{~nm}$. Calcite crystals of the raw cockleshell powder are oriented bars with a width of $500 \mathrm{~nm}$ and a length of 600-1700 nm.

Calcite nano-particle $\left(650^{\circ} \mathrm{C}-2 \mathrm{~h}\right)$ with size about $50-100 \mathrm{~nm}$ could be obtained after synthesis and heat treatment process (as shown in Figure 4). For recovering tooth surface, nano particles were found to be useful to spread over every surface and migrate into it effectively [8-9]. Therefore, calcite nano particle synthesizing in this study would be advantageous for tooth enamel restoration to treat enamel hypersensitivity. 


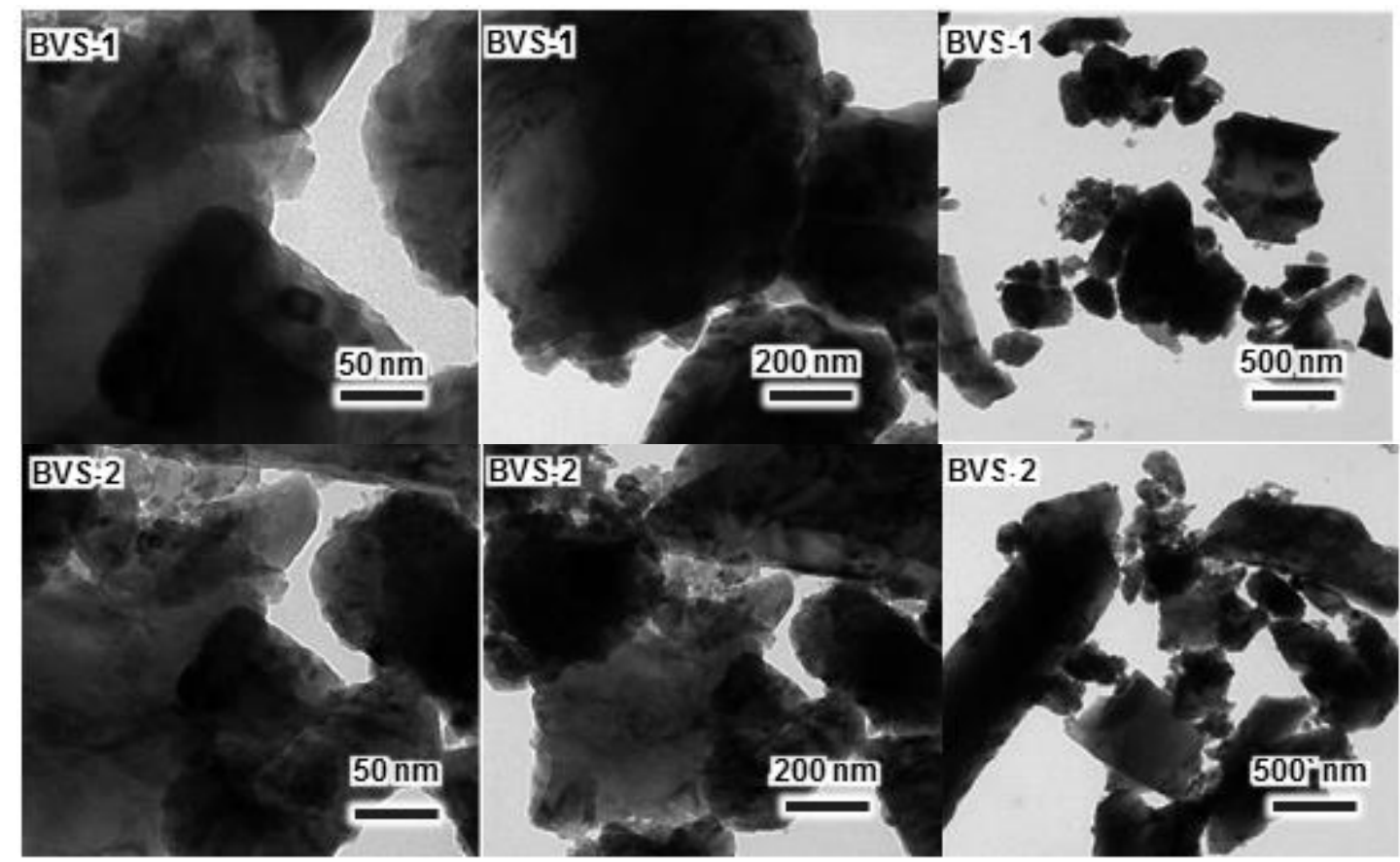

Figure 3. TEM images of the raw cockleshell powder (BVS) at different magnifications

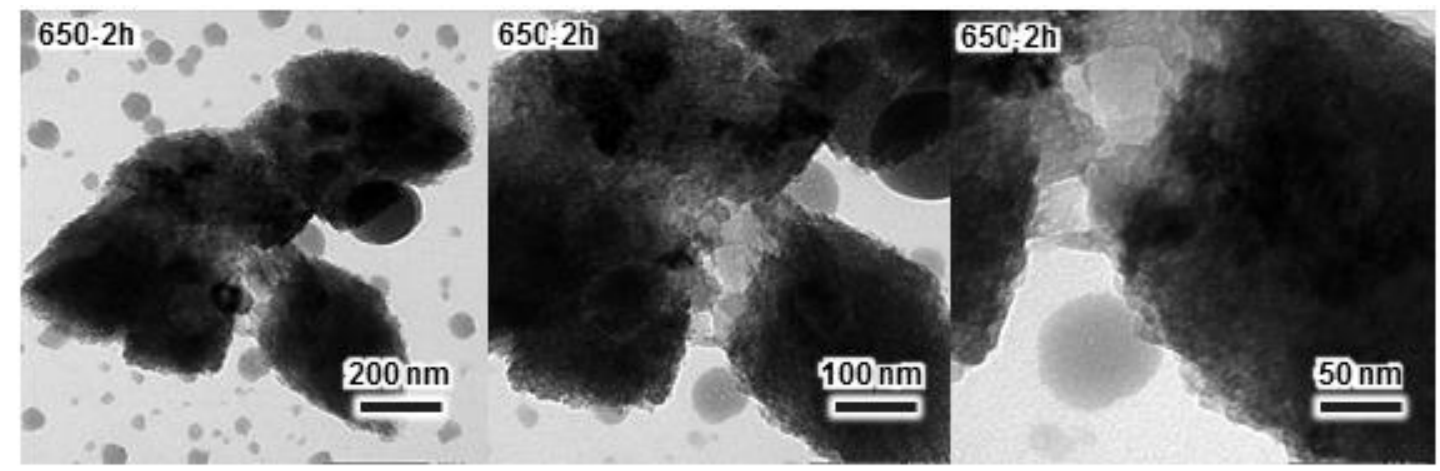

Figure 4. TEM images of powder calcined at $650^{\circ} \mathrm{C}$ soaking for 2 hours at different magnifications $\left(650^{\circ} \mathrm{C}-2 \mathrm{~h}\right)$

\section{Conclusions}

Based on the results, the synthesis of nano-calcite for the purpose of tooth enamel restoration to treat enamel hypersensitivity could be optimized as synthesis reaction was complete when it was carried out at $90^{\circ} \mathrm{C}$ and $100^{\circ} \mathrm{C}$. Next, pure calcite could be obtained when as-prepared powders were at $550^{\circ} \mathrm{C}, 600^{\circ} \mathrm{C}$ soaking for $6 \mathrm{~h}$ and $650^{\circ} \mathrm{C}$ soaking for $2 \mathrm{~h}$. Finally, under the heating conditions at $650^{\circ} \mathrm{C}$ for 2 hours, calcite nano-particle with size about 50-100 nm could be obtained. For the next studies, in vitro test need to be done to evaluate the dentinal tubule occlusion and surface mineralization effect.

\section{Acknowledgement}

The authors would like to thank Department of Biomaterials, Faculty of Dental Science, Kyushu University and Faculty of Materials Technology, Ho Chi Minh City University of Technology, VNU-HCM for laboratory cooperation. 


\section{References}

[1] J. Chen, and L. Xiang, "Controllable synthesis of calcium carbonate polymorphs at different temperatures," Powder Technology, Vol. 189, pp. 64-69, 2009. doi: 10.1016/j.powtec.2008.06.004

[2] K.N. Islam, M.Z.A. Bakar, M.M. Noordin, M.Z.B. Hussein, N. Rahman, and M.E. Ali, "Characterisation of calcium carbonate and its polymorphs from cockle shells (Anadara granosa)," Powder Technology, Vol. 213, No. 1-3, pp. 188-191, 2011. doi: 10.1016/j.powtec.2011.07.031

[3] M.C. Barros, P.M. Bello, M. Bao, and J.J. Torrado, "From waste to commodity: Transforming shells into high purity calcium carbonate," Journal of Cleaner Production, Vol. 17, No. 3, pp. 400-407, 2009. doi: 10.1016/j.jclepro.2008.08.013

[4] N. Nakatani, H. Takamori, K. Takeda, and H. Sakugawa, "Trans esterification of soybean oil using combusted oyster shell waste as a catalyst," Bioresource Technology, Vol. 100, No. 3, pp. 1510-1513, 2009. doi: 10.1016/j.biortech.2008.09.007

[5] M. Hariharan, N. Varghese, A.B. Cherian, P.V. Sreenivasan, J. Paul, and K.A. Asmy Antony, "Synthesis and characterisation of $\mathrm{CaCO}_{3}$ (calcite) nano particles from cockle shells using chitosan as precursor," International Journal of Scientific and Research Publications, Vol. 4, No. 10, 2014.

[6] A.B.Z. Zuki, Z. Norazri, and K. Zaleha, "Mineral composition of cockle (Anadara granosa) shells, hard clamp (Meretrix meretrix) shells and coral (Porites spp.): A comparative study," Journal of Animal and Veterinary Advances, Vol. 3, No. 7, pp. 445-447, 2004.

[7] A. Roy, S.S. Gauri, M. Bhattacharya, and J. Bhattacharya, "Antimicrobial activity of $\mathrm{CaO}$ nanoparticles," Journal of Biomedical Nanotechnology, Vol. 9, No. 9, pp. 1570-1578, 2013. doi: 10.1166/jbn.2013.1681

[8] S.Y. Lee, H.K. Kwon, and B.I. Kim, "Effect of dentinal tubule occlusion by dentifrice containing nano-carbonate apatite," Journal of Oral Rehabilitation, Vol. 35, No. 11, pp. 847-853, 2008. doi.org/10.1111/j.1365-2842.2008.01876.x

[9] P. Yuan, S. Liu, Y. Lv, W. Liu, W. Ma, and P. Xu, "Effect of a dentifrice containing different particle sizes of hydroxyapatite on dentin tubule occlusion and aqueous Cr (VI) sorption," International Journal of Nanomedicine, Vol. 14, pp. 5243-5256, 2019. doi:10.2147/IJN.S205804 